E International

\title{
Challenges in Better Co-ordinating Tokyo's Urban Rail Services
}



Discussion Paper 2016 19

Hironori Kato

Department of Civil Engineering,

The University of Tokyo, Japan 


\section{E International}

\section{Challenges in Better Coordinating Tokyo's Urban Rail Services}

\section{Discussion Paper No. 2016-19}

Prepared for the Working Group on

Public Transport Market Organisation and Innovation

\section{Hironori Kato}

Professor, Department of Civil Engineering, The University of Tokyo Japan 


\title{
The International Transport Forum
}

The International Transport Forum is an intergovernmental organisation with 57 member countries. It acts as a think tank for transport policy and organises the Annual Summit of transport ministers. ITF is the only global body that covers all transport modes. The ITF is politically autonomous and administratively integrated with the OECD.

The ITF works for transport policies that improve peoples' lives. Our mission is to foster a deeper understanding of the role of transport in economic growth, environmental sustainability and social inclusion and to raise the public profile of transport policy.

The ITF organises global dialogue for better transport. We act as a platform for discussion and prenegotiation of policy issues across all transport modes. We analyse trends, share knowledge and promote exchange among transport decision-makers and civil society. The ITF's Annual Summit is the world's largest gathering of transport ministers and the leading global platform for dialogue on transport policy.

The Members of the Forum are: Albania, Armenia, Argentina, Australia, Austria, Azerbaijan, Belarus, Belgium, Bosnia and Herzegovina, Bulgaria, Canada, Chile, China (People's Republic of), Croatia, Czech Republic, Denmark, Estonia, Finland, France, Former Yugoslav Republic of Macedonia, Georgia, Germany, Greece, Hungary, Iceland, India, Ireland, Israel, Italy, Japan, Korea, Latvia, Liechtenstein, Lithuania, Luxembourg, Malta, Mexico, Republic of Moldova, Montenegro, Morocco, the Netherlands, New Zealand, Norway, Poland, Portugal, Romania, Russian Federation, Serbia, Slovak Republic, Slovenia, Spain, Sweden, Switzerland, Turkey, Ukraine, the United Kingdom and the United States.

\author{
International Transport Forum \\ 2 rue André Pascal \\ F-75775 Paris Cedex 16 \\ contact@itf-oecd.org \\ www.itf-oecd.org
}

\section{ITF Discussion Papers}

ITF Discussion Paper series make economic research, commissioned or carried out in-house at ITF, available to researchers and practitioners. They describe preliminary results or research in progress by the author(s) and are published to stimulate discussion on a broad range of issues on which the ITF works. Any findings, interpretations and conclusions expressed herein are those of the authors and do not necessarily reflect the views of the International Transport Forum or the OECD. Neither the OECD, ITF nor the authors guarantee the accuracy of any data or other information contained in this publication and accept no responsibility whatsoever for any consequence of their use. This document and any map included herein are without prejudice to the status of or sovereignty over any territory, to the delimitation of international frontiers and boundaries and to the name of any territory, city or area. Comments on Discussion Papers are welcome. 


\begin{abstract}
This paper describes Tokyo's urban rail market, which has traditionally been privately funded and operated; and discusses policies aimed at better coordinating public transport services. Although the industry has delivered high quality infrastructure and services for most users, the existence of many different private operators and owners of tracks means that services and station facilities are not always well connected to one another. Individual private parties often lack sufficient incentives to invest in connectivity improvements, such as installing elevators in stations or implementing missing connections between lines, since these do not usually directly increase their profits. Three case studies explore different policy responses to the challenge of balancing competing wishes of private actors with the needs of travellers. In all cases the government has intervened through legislation and grants to try to stimulate connectivity investment and to do so in consultation with local communities. The recent government interventions into the Tokyo rail market represent a gradual evolution in market structure with the goal of better meeting social needs.
\end{abstract}




\section{Table of Contents}

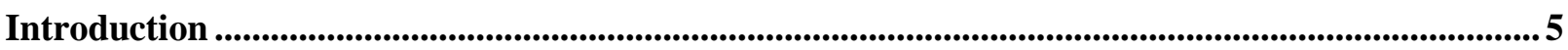

Challenges of private rail markets in Japan's metropolitan areas ...................................................5

Efforts to improve urban rail connectivity in Tokyo .................................................................................... 7

Direct-through rail operations between suburban rail and metros ...................................................



Why poor coordination remains in Tokyo's urban rail ..............................................................................11

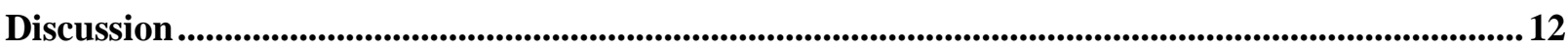

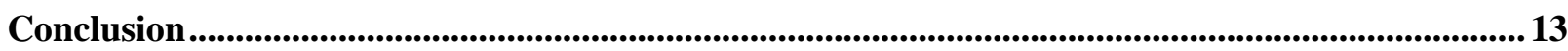

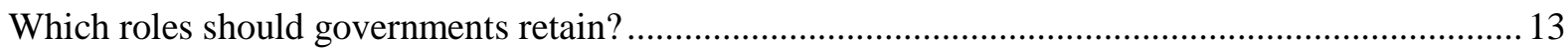

Have reforms generated meaningful competition in all cases? ......................................................... 13

Do shifts in population demographics and urban form disrupt established tendering and organisation

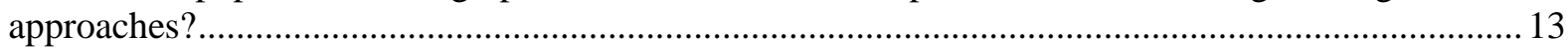

What are the challenges in coordinating PT services with urban redevelopment?.............................13

References ................................................................................................................................................................. 14

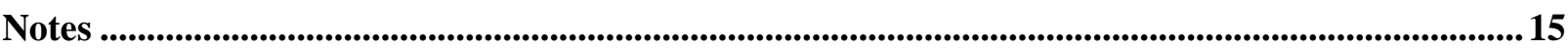

\section{Figures}

Figure 1. Direct-through rail network in Tokyo and time-series changes ............................................. 8

Figure 2. Share of stations with a non-step route, Braille tiles, and toilet for mobility impaired users in Japan .....

Figure 3. Finance structure of projects to "Enhance Convenience of Urban Railways" under the Act ... 10 


\section{Introduction}

Many governments have deregulated their urban public transport (PT) markets mainly by reducing government controls on PT services while seeking greater competition among private enterprises. Typically, governments have shifted the urban PT system from their direct planning and operation to private operations under government guidance. This shift could improve the efficiency of urban PT markets to some extent, but it may also bring new challenges. Private firms pursue profits from PT services whereas governments tend to seek social welfare from PT. This difference often causes a mismatch in the goals of the urban PT market, which can lead to poor performance of PT services. For example, the improvement of intermodal connectivity, such as between bus and rail or car sharing and trams, is one of the highest priorities for governments while it may be less important for PT private operators, who are concerned only with the profitability of their own services.

To realise an integrated urban transportation market, it is essential to balance transportation strategies that incorporate multiple perspectives of different stakeholders, including both private and public players. This may prove quite challenging in practice since solutions will depend on sociodemographic, geographical, technical, historical, or cultural conditions of a given PT market. In addition, emerging technologies, such as electric vehicles, management systems based on information and communication technology, and new sharing concepts, could influence the choice among strategies. The best solutions would satisfy a government's targets while not losing the advantages of private sector participation, such as their financing capacity for infrastructure investment and their drive to improve operational efficiency.

This paper reports three cases pertaining to efforts made for better coordination between the private sector and/or between the public and private sectors in the urban rail market in Tokyo, which has a relatively long history of a private-oriented market. Then, implications are drawn from these cases and further issues are raised regarding market regulations and the role of the government in the PT market.

\section{Challenges of private rail markets in Japan's metropolitan areas}

Japan's main metropolitan areas-Tokyo, Osaka, and Nagoya-have dense and widespread urban rail networks, which provide high-performance urban transport services. This has contributed not only to the daily lives and business activities of local people, but also to higher productivity and better international competitiveness. In particular, Tokyo is well known as a rail-oriented megacity in which huge traffic demand generated from a population of more than 30 million has been handled well with a sophisticated urban rail system.

As shown by Kato (2014), one of the unique characteristics of Tokyo's urban rail market is that many rail services are provided by private rail companies. More than 20 private rail operators provided rail services in the Tokyo Metropolitan Area as of 2015, and most owned and operated their rail infrastructure. As is the case elsewhere in Japan, rail operators in Tokyo have unique use of rail infrastructure for their operations (although rail operations could be separated from rail infrastructure 
ownership, e.g. with one company providing rail services using rail infrastructure owned by another organisation). This means that urban rail operations in Tokyo are regionally monopolistic.

Private operation and development of urban rail has positively influenced the operating efficiency of urban rail services in Tokyo. For example, multiple private rail operators often provide competing services connecting the same pair of cities with different routes, which leads to lower fares and faster service to attract more ridership. One such example is the competition among three rail operators: JR East, Keikyu Co., and Tokyu Co., all of which connect Tokyo to the city of Yokohama using three different lines. Another example is airport access from the central business district (CBD) in Tokyo to Narita Airport, which is provided via different routes of two rail operators: JR East and Keisei Electric Railway Co. In addition, they provide travellers with multiple route options, which improve the robustness of airport access service in Tokyo.

Although such a private-oriented urban rail market contributes to efficient transportation services in Tokyo, it sometimes suffers from poor coordination among different services. A typical issue relating to poor coordination in Tokyo's urban rail network is connectivity at rail stations. As the Tokyo Metropolitan Area grows geographically, average travel distances become longer. The dispersal of activities also means that many urban rail users in Tokyo have to change trains at least once at connection stations, even in a single journey. According to Kato et al. (2003), more than 80 per cent of travellers using rail for home-to-work and home-to-school journeys change trains at connection stations at least once in the Tokyo Metropolitan Area. Connectivity issues can include physical separation between platforms that increases travel time, physical barriers, such as steps for mobility-impaired people and exposure to rain, snow, and wind without protection along connection routes between stations. There are many poorly performing connection stations in Tokyo. Kato et al. (2003) reported there are more than 30 stations where the walking time between platforms (either within a single station, or between two adjacent stations) is more than 7 minutes.

Another issue relating to the poor coordination of Tokyo's urban rail network is a missing link problem. A missing link is an unlinked space between two rail stations that are closely located in a distance of typically less than $1 \mathrm{~km}$. Suppose there are two stations, both of which are the terminal stations of two different lines, located close to each other. Under such conditions, passengers who want to connect between the lines need to walk or use other transportation modes, such as bike-sharing or short-distance bus. If a new rail line connecting the two stations were to be constructed, passengers could pass directly through the two rail lines without transfer, which should save travel time, reduce the fatigue of walking, and even improve traffic safety. Unfortunately, many missing links remain in Tokyo's urban rail network. For example, Tokyu Kamata station, a terminal of the Tokyu Tamagawa line, is located about 800 m from Keikyu Kamata station, which is located along the Keikyu Airport line. Tokyu Kamata station belongs to one private company, Tokyu Co., whereas Keikyu Kamata station belongs to another private company, Keikyu Co. If a $800 \mathrm{~m}$ line were introduced to connect the two stations, many areas in the western part of Tokyo and Saitama Prefecture, including the major cities of Shibuya, Shinjyuku, and Ikebukuro, could be connected directly with Haneda Airport, one of Tokyo's international/domestic airports, by direct-through trains. This would be expected to generate huge social benefits. Although the new line has been proposed for a decade, there has been no consensus on who would build the link and operate services given the newly coordinated services would operate across two different operators' lines. 


\section{Efforts to improve urban rail connectivity in Tokyo}

Many measures have already been taken to overcome Tokyo's urban rail connectivity problems, which have been recognised widely. This study considers three efforts made in the past: direct-through rail operations, the Barrier-Free Act, and the Act to Enhance the Convenience of Urban Railways.

\section{Direct-through rail operations between suburban rail and metros}

Currently, many suburban rail services feed directly into the metro network in the CBD of Tokyo. This so-called "direct-through operation" enables passengers to change from a suburban rail line to a metro line while remaining on their original railcars without physical transfers between connecting stations. The alternative would be for suburban and metro services to operate independently, with each actor operating services on their own tracks. By avoiding the time and inconvenience of transferring between services, direct-through operation delivers large benefits to travellers. In addition, it is in line with the government policy that aims to reduce in-station congestion and realise an efficient and convenient urban rail network, which improves economic productivity in Japan's capital city.

However, huge construction costs for new tunnelling and signalling systems, among other things, are required to allow interoperability of two distinct lines. The introduction of direct-through rail operation has been guided by long-term urban rail investment plans, which are proposed by a council commissioned by the Minister of Land, Infrastructure, Transport and Tourism as of 2015. The plan has no statutory power to force rail operators to follow the proposal. Usually, the investment necessary to realise the direct-through service is jointly funded by private suburban rail companies and the two government-backed metro operators. ${ }^{1}$

Investments in direct-through operation benefit both suburban rail and metro operators because the improved convenience for commuters leads to greater housing demand along the rail lines in neighbourhood suburban areas, increasing rail ridership, and hence additional profits for suburban rail operators. In addition, rail depots that used to be located in urbanised areas are removed or relocated to rural areas, which could reduce their maintenance costs, or even give them another opportunity to redevelop the former depots into more profitable businesses.

Direct-through operation was first proposed by the Council for Urban Transport in 1956 and has been introduced in the Tokyo Metropolitan Area gradually since then as it provides a win-win-win solution for urban rail passengers, the government, and rail operators. As of 2010, the total length of rail network under direct-though operations reached about $880 \mathrm{~km}$, or more than 35 per cent of the total urban rail network in the Tokyo Metropolitan Area, as shown in Figure 1. This approach inspired the interconnection of RER, the SNCF's suburban lines with metro lines in Paris (Sato and Essig, 2000). 
Figure 1. Direct-through rail network in Tokyo and time-series changes

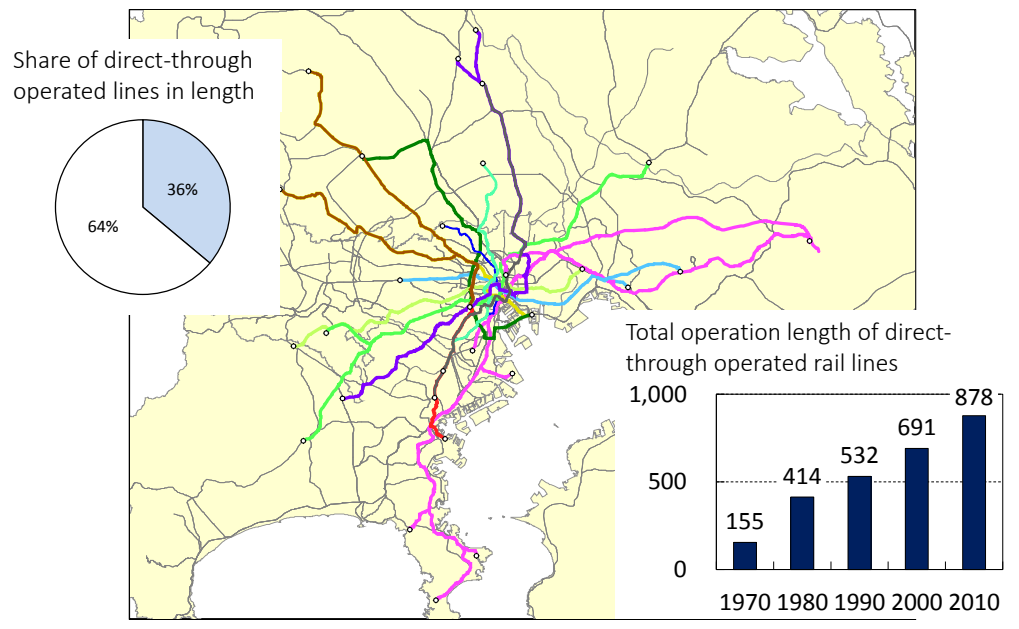

Source: adapted from Council for Transport Policy (2014)

\section{Barrier-Free Act in 2000 and related subsidy schemes}

Mobility for people with mobility impairments has been highlighted as one of Tokyo's policy priorities since 2000. One of the reasons is that Tokyo has been experiencing rapid population ageing. There are strong expectations of an increase of aged rail users who may have mobility impairments in the coming super-aged society in which more than 30 percent of the population will be 65 years or older. The development of a seamless urban rail network has become one of the policy targets for the national government, as shown in the long-term urban rail development plan of 2000 (Kato, 2014). Another reason is that the government shifted its policy focus from investment quantity to asset quality after 2000. Construction of new rail lines used to be the main issue in urban rail planning until the 1990s, when rail capacity was so poor that in-vehicle congestion was serious in Tokyo. However, in-vehicle congestion gradually has become less serious owing to both the decrease of rail demand and previous capacity investments (Kato, 2014).

The national government introduced the Barrier-Free Act in 2000. "Barrier-free" means a removal of barriers or obstacles for those who have mobility impairments that can hamper their participation in society. The barriers include not only physical obstacles but also social, institutional, and psychological ones. The Act requires mandatory installation of facilities so that technical standard (standard for smooth mobility in public transport) given by the Act are satisfied at newly introduced rail stations or at rail stations where a large-scale improvement is done; while it also requires rail station operators to make efforts to satisfy the technical standard at existing rail stations. The technical standard consists of ten requirements for rail stations, including an installation of elevators and/or slopes for removing physical steps from paths connecting station entrances with platforms; a preparation of space with sufficient width for wheelchair users; non-step or nearly non-step connection between train floors and platform floors; installation of station facilities for avoiding unintended downfall of visually impaired persons from platforms such as screen platform doors, movable fences, and Braille tiles. The national government set a policy target that all rail stations whose daily passengers numbered 5,000 or more satisfy the technical standard by 2010. According to a government review, as of March 2010, 78 per cent of rail stations whose daily passengers numbered 5,000 or more had installed barrier-free facilities, as shown in Figure 2 (MLIT, 2012). As the further growth of the number of aged rail users is expected in the coming decade, the national government revised the Act in 2011 with a new policy target: that 100 per cent of rail stations whose daily passengers number 3,000 or more must satisfy the technical standard. According to 
an updated government review, as of March 2015, rail stations with 3,000 or more daily passengers and that have installed barrier-free facilities comprise 96.6, 89.4, 97.0, and 95.1 per cent of the total in Saitama, Chiba, Tokyo, and Kanagawa prefectures respectively (MLIT, 2015).

Figure 2. Share of stations with a non-step route, Braille tiles, and toilet for mobility impaired users in Japan



Source: adapted from Yamashita (2015)

The national government has introduced subsidy schemes to support the introduction of barrier-free facilities in rail stations. One such scheme is the "subsidy for sustenance and improvement projects in regional public transport", which replaced a similar scheme in 2011. Under the new scheme, both the national and local governments provide subsidies to rail companies of up to one-third of the total cost. This scheme covers rail stations with daily passengers of 3,000 or more. To be eligible for funds, the scheme requires the relevant local government to set up a council of local stakeholders which collects opinions from the public to inform the investment plan. Where two or more rail operators service at a given station, it is possible to coordinate these different rail companies through their membership of the relevant council. In addition, the council system has another advantage in that the rail station facilities may be coordinated with urban planning in the neighbourhood of the rail station because urban planners from local governments usually are required to participate in the council. Thus, the rail station development could be harmonised with urban redevelopment under the guidance of the council.

\section{Act to Enhance the Convenience of Urban Railways in 2005}

The Act to Enhance the Convenience of Urban Railways was enacted in 2005, and aims to improve the quality of urban rail services in metropolitan areas: Tokyo, Kinki, including Osaka, and Chukyo, including Nagoya. The Act deals with projects that "enhance the convenience of urban railways," in either of two ways: increasing the speed of rail services (ISRS) or smoothing mobility in rail stations (SMRS). ISRS investments aim to reduce travel time for rail users by constructing new rail links connecting existing rail lines while the SMRS investments aim to reduce transfer time in rail stations and remove difficulties in the use of other rail station facilities by improving routes for seamless connections within existing rail station facilities. 
Under the Act, both project types assume the separation of rail operators from the infrastructure constructor/owner. The latter can receive a grant equivalent to one-third of the construction cost from the national government and a further third from the local government. The remaining construction cost is paid by the infrastructure constructor/owner itself through debt finance, which in turn is funded by access (user) charges paid by operators for use of the track (Figure 3). The Act stipulates that the infrastructure constructor/owner should be either a semi-government corporation ${ }^{2}$ or the Japan Railway Construction, Transport and Technology Agency (JRTT). ${ }^{3}$

Figure 3. Finance structure of projects to "Enhance Convenience of Urban Railways" under the Act

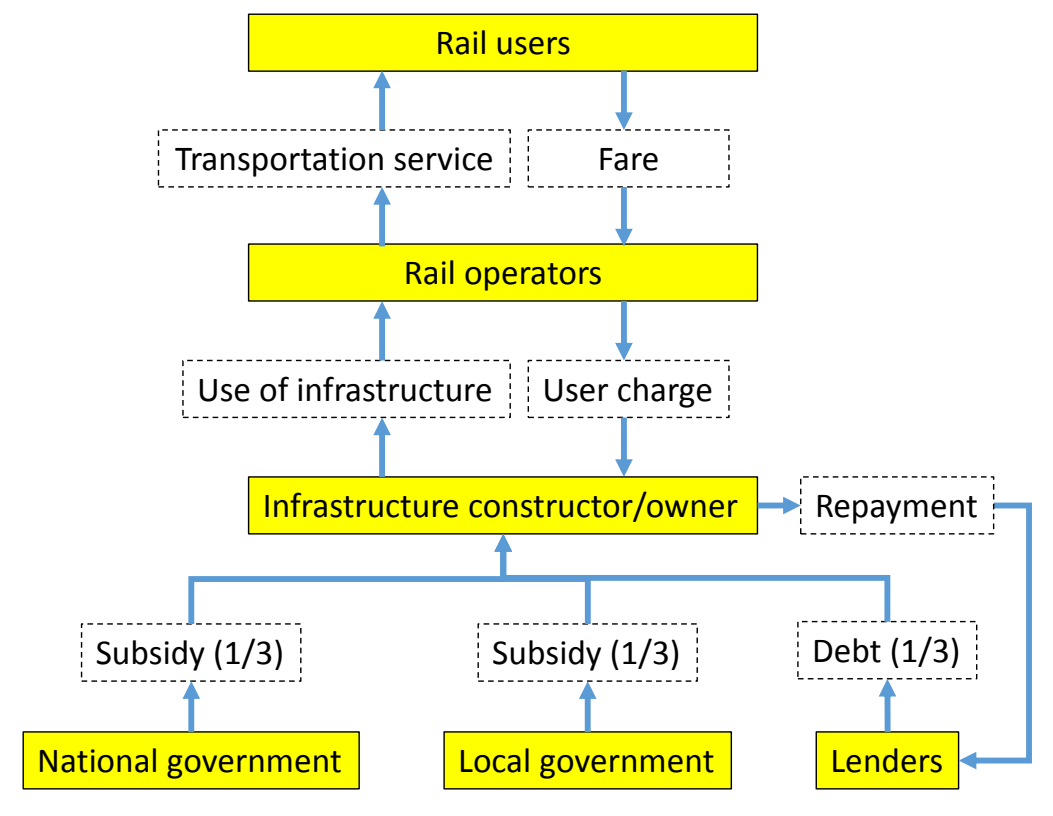

The incremental charge paid by the rail operators to fund the infrastructure constructor/owner's contribution to the project is determined based on excess profits accruing to the rail operators as a result of the project. The excess profit of each rail operator is calculated by subtracting the expected profit of the operator in the case without infrastructure investment from that in the case with investment. The expected profits in both cases are estimated using travel demand forecasts, in which profit is defined as revenue minus the cost of operating both existing and new infrastructure.

The Act requires the local government to set up a council that consists of local stakeholders, including the rail operators, infrastructure constructor/owner, and local government for SMRS projects (similar to the Barrier-Free Act), but it does not require them to set up a council for ISRS projects. For the latter projects, the Act stipulates that the rail operators and infrastructure constructor/owner should voluntarily agree on the project, including the charge. However, in case they cannot reach agreement, the Act permits the minister to arbitrate disputes between them.

The Act has some strengths that may assist in solving the missing link problem and poorly coordinated connection stations in the metropolitan areas. Yokota (2012), who interviewed stakeholders in on-going projects using the Act, summarised the advantages of the Act as follows: (1) the subsidy rate is higher than other schemes so encourages new projects; (2) the excess profit covers the changes in the operator's profit stemming from existing services in networks other than the new infrastructure; (3) no additional fixed initial fare is levied on the newly introduced line (for ISRS projects removing a missing link); (4) the consultation process is institutionalised so that consensus is built easily (for SMRS 
projects); and (5) the rail station can be improved in coordination with neighbourhood urban development (for SMRS projects).

The Act assumes that the rail companies will voluntarily propose new ISRS projects to remove missing links. Their main incentive for voluntary actions is the grant from the national and local governments, whose rate is higher than that of other schemes. However, this Act may have some drawbacks. One is an unclear process for determining the charge paid by the rail operators to the infrastructure constructor/owner. This may seem a risk for the rail operators. The charge is determined basically through the demand forecasting result, which itself may have some uncertainties. Another uncertainty is that the Act does not state the period of the charge payment clearly. Theoretically, the rail operators should keep paying the charge to the infrastructure constructor/owner, even after the debt finance of the owner is completed, until the total amount of the payment charge reaches the total investment cost. These uncertainties can limit the willingness of private operators to propose such projects. As of 2015, only three projects have applied to access the scheme since the Act was introduced 10 years ago.

\section{Why poor coordination remains in Tokyo's urban rail}

Although much progress has been made, as described above, poor connection stations and missing links remain in Tokyo. Why have these problems not been solved? The reasons may vary depending on the local context of each case, but may be summarised generally into the following five reasons.

First, investment for improving connectivity may not be profitable for private rail companies although it contributes to enhancing user's convenience or generating positive social benefit. This is often true because fare collection from the in-station or station-to-station connection is technically impossible or expensive, and this leads to poor motivation for private companies to invest in connection facilities. However, development of a new ICT system to collect fares from connection could overcome this problem by lowering the costs of measuring users moving between different operators' systems.

Second, private companies tend to have a narrower scope in which they consider only existing resources. In particular, in a shrinking market, such as Japan's urban rail market, their business style should be conservative, in which they focus on keeping current services, and this may give them poor incentives to have the broader perspective of improving the entire urban transport network. This suggests that socio-demographic changes influence the motivation of private companies to improve the PT service.

Third, the private companies may not want to cooperate with rival companies to avoid losing their existing customers. Even if both companies could gain positive benefits in the long run through cooperation, they tend to form their strategies from short-term viewpoints only. This suggests that governments should play an important role in proposing long-term transportation strategies beyond the short-term horizons of private companies.

Fourth, private companies do not want to face the burden alone of an investment cost to improve connectivity. In the practice of rail development in Japan, there is an implicit rule that a proposing player should pay the entire project cost, even if that project could benefit other stakeholders; this makes private rail companies hesitate to propose a new project. This suggests that a planning process that proactively encourages private companies to propose projects should be institutionalised. 
Fifth, many areas that require the improvement of rail service connection already have been so urbanised that new construction has become expensive. In addition to the difficulties of land acquisition, construction in urbanised areas requires high-skilled engineering work to avoid noise/vibration emissions, damage to existing facilities, and suspension of neighbourhood economic activities. These may be regarded as investment risks by private companies, suggesting that the investment risk may need to be shared by both private and public sectors, possibly through public-private partnership, when the investment contributes to social benefit.

\section{Discussion}

What policy implications are derived from the abovementioned cases for promoting better connectivity? Five implications are summarised as follows. First, the cases reveal that one of the most important factors for success is a mechanism to give incentives to private companies to participate voluntarily in the connectivity improvement projects. In this sense, the direct-through operation appears more successful than the Act to Enhance the Convenience of Urban Railways. The incentive mechanism should be designed carefully by governments.

Second, evidence from the three cases shows that the institutionalisation of the decision-making process is critical to ensuring broader objectives can be met. For instance, the Barrier-Free Act and the SMRS projects under the Act to Enhance the Convenience of Urban Railways require local governments to establish councils at which multiple stakeholders should join the discussions. This enables private companies to negotiate with other stakeholders.

Third, subsidies to private companies can provide companies with incentives to support the government's policy goals but their effectiveness depends on project design. This is because the private companies are so sensitive to uncertainties that they may hesitate to participate in projects when they consider that they include significant risks for their business. Careful design of the subsidy scheme is therefore required for public-private partnerships.

Fourth, the change in Tokyo's socio-demographic pattern toward rapid ageing is likely to continue to affect the PT market design, including the government subsidy scheme and regulations. The shrinking market makes private companies conservative in their business style while social needs for improving the PT service may increase. Governments should play a role in promoting better PT service from private companies since the companies themselves will not have sufficiently strong motivation to act alone.

Finally, technological developments relating to fare collection in particular could influence private companies' motivation for connectivity-improving projects. To realise a more universal fare collection system, technological development should be made in more sophisticated smartcards or new mobile phone-based devices. 


\section{Conclusion}

This study investigated three cases of efforts made to improve the coordination of urban rail services in Tokyo among private companies and government. Japan's rail market has developed differently to other countries. However, it is still unlikely that it is too exceptional to provide implications for other countries. Tokyo's cases suggest some answers to the following four questions regarding PT market organisation and innovation.

\section{Which roles should governments retain?}

Tokyo's urban rail experience suggests that governments should guide stakeholders toward better coordination because private companies often have difficulties cooperating voluntarily with others. Poor coordination causes substandard PT network connectivity. The government should provide private companies with opportunities to participate in discussions for a harmonised transportation market as well as financial incentives to invest.

\section{Have reforms generated meaningful competition in all cases?}

From the evidence of the long history of competition in Tokyo's urban rail market, competition really is meaningful. In some major intercity routes, there is competition among lines and operators. This contributes to better service and lower fares. At the same time, Tokyo's experiences may indicate such competition among rail operators could cause poor coordination in the PT market. Our case study may suggest that introducing public and stakeholder involvement may be essential to deliver better social outcomes rather than purely competitive ones. For such coordination, the government should have an important role to encourage harmonised competition in the PT service.

\section{Do shifts in population demographics and urban form disrupt established tendering and organisation approaches?}

Tokyo has experienced rapid ageing and shrinking urban area. Although Tokyo's urban rail system continues to be a private-oriented rail market, the increase of aged or mobility-impaired PT users in the future will require more investment for barrier-free facilities and connection improvement, both of which may not be profitable for PT companies. As a private-led operation system may not work well for meeting such social needs, it should be changed gradually to a system more like a "public-private partnership." The recent efforts made in Tokyo's urban rail market for better connectivity could be regarded as part of a long-run institutional transition to meeting social needs.

\section{What are the challenges in coordinating PT services with urban redevelopment?}

Tokyo's barrier-free facilities provide one example of a difficulty of coordinating PT services with urban redevelopment. Rail station facilities are managed by rail companies, whereas redeveloped areas are usually managed by urban developers; thus, coordination between the rail station and redeveloped areas is often a difficult task for both the rail companies and the urban developers. One of the solutions in Tokyo is a council system in which different players are involved in discussions about integrating design of urban and station facilities. At the same time, the national and local governments jointly provide subsidies to rail companies only when a coordinated project plan is prepared. 


\section{References}

Council for Transport Policy (2014) "Current situations and challenges of urban rail in the Tokyo Metropolitan Area (Supplementary data)," Slides presented at the first meeting of Railway Committee, Division of Surface Transport, Council for Transport Policy held on May 7, 2014. (in Japanese)

Kato, H., Shikai, J., Kato, S., Ishida, H. (2003) "Cost-benefit analysis for improvement of transfer service at urban railway stations," World Transport Research: Selected Proceedings of the 9th World Conference on Transport Research.

Kato, H. (2014), "Urban Rail Development in Tokyo from 2000 to 2010", International Transport Forum Discussion Papers, No. 2014/05, OECD Publishing, Paris. DOI: http://dx.doi.org/10.1787/5jz40rjddtf4-en

Ministry of Land, Infrastructure, Transport and Tourism, Japan (MLIT) (2012) "Final Report of Research Committee on Current Problems and Future Direction of Railway Development in the Tokyo Metropolitan Area" (in Japanese).

Ministry of Land, Infrastructure, Transport and Tourism, Japan (MLIT) (2015) "On the progress of barrier-free stations by prefecture as of March 31 2015," http://www.mlit.go.jp/common/001057219.pdf, last accessed on September 6, 2015 (in Japanese).

Sato, L. and Essig, P. (2000) "How Tokyo's subways inspired the Paris RER (Interconnection with SNCF suburban lines)," Japan Railway \& Transport Review, Vol.23, pp.36-41.

Yamashita, S. (2015) "Promotion of barrier-free policy and universal-design-oriented policy," Slides presented at the second meeting of the First Division, Committee for Improvement of "Quality of Life," Cabinet Secretariat, February 3, 2015. (in Japanese)

Yokota, S. (2012) "A study on how to promote the utilization of the subsidy scheme for urban railways: Focused on 'Act on Enhancement of Convenience of Urban Railways, etc.," Transport Policy Studies' Review, Vol.15, No.3, pp.18-28 (in Japanese). 


\section{Notes}

${ }^{1}$ There are two metro operators in Tokyo: a public organisation, the Tokyo Metropolitan Government; and the government-owned Tokyo Metro Ltd. Co., formerly the Teito Rapid Transit Authority, which was corporatised in 2004.

${ }^{2}$ The shareholders of a semi-government corporation are typically local governments and private rail operators.

${ }^{3}$ The JRTT is an independent administrative institution, which is involved in construction and technical support for railway and other transportation projects throughout Japan.

${ }^{4}$ A new fare table, including the initial fare, should be applied only to the newly introduced rail section if that infrastructure would be independently owned and operated by a different company. This means rail users who pass through the section should pay three charges to the three rail companies: the existing two rail companies plus the new rail company who operate the new section. However, the act permits the rail operators to apply the existing fare tables even for the newly introduced rail section, and thus, rail users who pass through the section should pay the two charges only to the existing rail operators. 
